\title{
Cognitive impairment in substance use disorders
}

\author{
Tatiana Ramey (1D, ${ }^{\prime *}$ and Paul S. Regier ${ }^{2}$
}

\begin{abstract}
${ }^{1}$ Division of Therapeutics and Medical Consequences, National Institute on Drug Abuse, National Institutes of Health, Rockville, Maryland
${ }^{2}$ Center for Studies of Addiction, Department of Psychiatry, University of Pennsylvania Perelman School of Medicine, Philadelphia, Pennsylvania
\end{abstract}

Cognitive impairments in substance use disorders have been extensively researched, especially since the advent of cognitive and computational neuroscience and neuroimaging methods in the last 20 years. Conceptually, altered cognitive function can be viewed as a hallmark feature of substance use disorders, with documented alterations in the well-known "executive" domains of attention, inhibition/regulation, working memory, and decision-making. Poor cognitive (sometimes referred to as "top-down") regulation of downstream motivational processes-whether appetitive (reward, incentive salience) or aversive (stress, negative affect)—is recognized as a fundamental impairment in addiction and a potentially important target for intervention. As addressed in this special issue, cognitive impairment is a transdiagnostic domain; thus, advances in the characterization and treatment of cognitive dysfunction in substance use disorders could have benefit across multiple psychiatric disorders. Toward this general goal, we summarize current findings in the abovementioned cognitive domains of substance use disorders, while suggesting a potentially useful expansion to include processes that both precede (precognition) and supersede (social cognition) what is usually thought of as strictly cognition. These additional two areas have received relatively less attention but phenomenologically and otherwise are important features of substance use disorders. The review concludes with suggestions for research and potential therapeutic targeting of both the familiar and this more comprehensive version of cognitive domains related to substance use disorders.

Received 15 March 2018; Accepted 24 September 2018; First published online 28 December 2018

Key words: Attention, decision-making, executive function, inhibition, metacognition, precognition, social cognition, substance use disorders, theory of mind, working memory.

\section{Introduction}

Cognitive alterations and deficits that are observed in substance use disorders ${ }^{1}$ contribute directly and indirectly to the overall tremendous public health burden that these disorders place on society. Broadly, drug and alcohol use in human populations exists on a continuum $^{2,3}$ ranging from nonpathological to levels of substance use diagnosed as a mental health disorder in the Diagnostic and Statistical Manual of Mental Disorders (DSM). ${ }^{4}$ Here, we discuss cognitive changes that are on the spectrum where drug use already represents a disorder. This type of drug use can be defined as a "pathological pattern of behaviors related to use of the substance," characterized by a compulsive and chronically relapsing pattern of drug use, impaired control over substance use, continuation of use despite negative consequences, craving, tolerance, and withdrawal. ${ }^{4,5}$ The

* Address for correspondence: Tanya (Tatiana) Ramey, Division of Therapeutics and Medical Consequences (DTMC), National Institute on Drug Abuse, National Institutes of Health, Rockville, Maryland.

(Email: tanya.ramey@nih.gov) typical cognitive domains contributing to this understanding of addiction are attention, response inhibition, decision-making and working memory.

Recently a new systemic conceptual framework for neuroscience, the Research Domain Criteria (RDoC) National Institutes of Health initiative, was launched. ${ }^{6}$ RDoC is a framework for analyzing mental processes, wherein disorders are considered in terms of disruptions along the continuum of normal to pathology across the full range and along the elemental psychological processes and behavioral functions. This approach is increasingly being used in research, where an appreciation and understanding of its utility is building. RDoC is applied transdiagnostically along the continuum of normal-pathology for the domain or construct in question, allowing one to step away from categorical diagnoses. $^{7}$

The RDoC approach has recently been applied to substance use disorders. ${ }^{8}$ Three addiction-relevant domains were highlighted-executive function, incentive salience, and negative emotionality. ${ }^{9}$ These functional domains roughly correspond to classical stages in 
the addiction cycle, and they can also be viewed as concurrent contributors to addiction and relapse vulnerability (see Figure 1). These three domains, intended to cover the core elements of the addiction cycle as a disorder, can be measured across a variety of substance use disorders. In this review we will focus on the executive (cognitive) domain, providing an overview of impairments that may serve as intermediate phenotypes for (behavioral, pharmacologic, or neurostimulatory) intervention.

This overview proposes to extend the three established cognitive domains in substance use disorders to include (1) precognition, featuring processes that occur outside or before conscious cognition per se; and (2) social cognition, including metacognition/ insight theory of mind (ToM). These expanded domains may be an integral part of the human addiction phenotype and could potentially hold the key to aspects of the addiction phenotype that make treatment and functional impairments in substance use disorders so challenging (Figure 1).

Several models of addiction address cognitive impairments that either predispose a person to addiction or

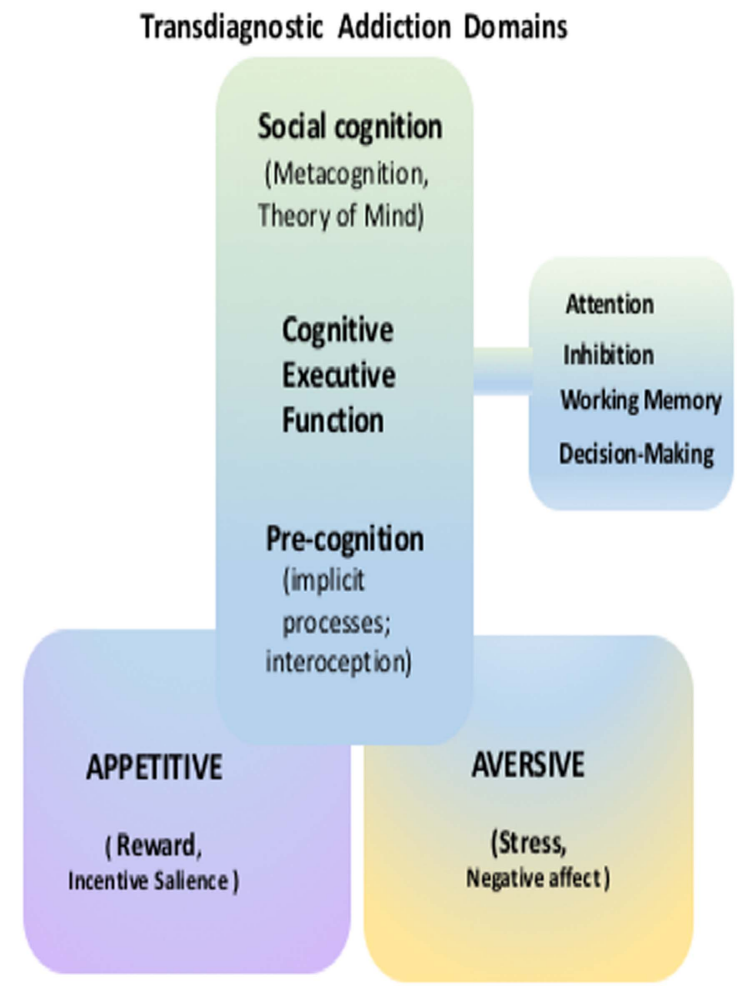

FIGURE 1. A visual representation of several transdiagnostic research domains of addiction. Substantial prior research has been conducted on fundamental alterations in the appetitive and aversive motivations processes. The focus of the current paper is a continuum of cognition, ranging from precognitive (implicit) processes to classical executive function (attention, inhibition, working memory, and decision-making) and social cognition (metacognition theory of mind). result from drug exposure. For example, Goldstein and Volkow ${ }^{10}$ proposed a model in which disrupted cortical top-down processes are a result of prefrontal cortex (PFC) dysfunction that leads to impaired response inhibition and salience attribution. ${ }^{10,11}$ In other words, there is a decreased ability to modify behavior related to drug and drug cues (response inhibition impairment) coupled with an abnormal salience (salience attribution change) of drug and drug-related cues. ${ }^{10}$ Other models emphasizing cognition include Monterosso and Ainslie's description of impulsive choice in humans as a hyperbolic (rather than exponential) function. ${ }^{12}$ They argue that impulsive behaviors (e.g., the preference for smaller, more immediate rewards vs. larger, more delayed rewards) often result from a breakdown of cognitive self-control mechanisms. Bickel and Marsch $^{13}$ expanded on this model and applied it to addiction, showing that individuals with addiction discount delayed rewards to a much greater extent than healthy controls. ${ }^{14}$ Sofuoglu and colleagues ${ }^{15}$ proposed a dual-process model, wherein a balance between "top-down" and "bottom-up" processes compete for control of behavior. They argue that neurobiological bottom-up processes are implicit and more automatic, and when heightened, increase the risk of drug use and relapse. Executive top-down processes, impaired in individuals with addiction, are more deliberative and are responsible for modulating the downstream (more automatic) processes.

\section{Attention}

Addiction is characterized by a strong attentional preference for drugs and drug-related cues. ${ }^{16-18}$ Attentional biases are often implicit ${ }^{19}$ and occur automatically. ${ }^{20}$ Some researchers suggest that drug-related cues gain positive incentive properties through a classical conditioning process, ${ }^{21,22}$ while other researchers posit that negative affect can increase the salience ("attentiongrabbing" quality) of drug-related cues, ${ }^{23}$ both of which facilitate drug-seeking behaviors. Whether established through positive or negative motivation, attentional bias can then drive drug seeking, ${ }^{24}$ reflected in a shift of salience for drug-related cues and behavioral resources being directed toward the goal of drug consumption.

There are several tasks used to measure attentional bias. The Stroop interference task asks individuals to name the font color of several words; interference occurs when the content of the word is different from the font or is emotionally charged (drug words), ${ }^{25}$ resulting in a slower reaction time. Generally, users of nicotine, ${ }^{26-28}$ cocaine ${ }^{29,30}$ heroin, ${ }^{30-33}$ cannabis, ${ }^{34,35}$ and alcohol ${ }^{36}$ have slower reaction times when encountering words associated with their substance use disorders. Visual attention tasks can also reveal accelerated reaction times to drug-related stimuli. ${ }^{37-40}$ Illustrating that attention 
may drive approach, other tasks have measured the attention-driven approach to drug-related cues using a "joystick" procedure. In these tasks, participants either push (avoidance) or pull (approach) a joystick in response to drug-related cues, whether explicit or implicit. ${ }^{41}$

Researchers have begun using these tasks to alter attentional biases (e.g., attentional bias modification training) in an attempt to decrease drug use. Results have shown that attentional bias modification can reduce bias to alcohol cues ${ }^{41-44}$ but not cocaine cues. ${ }^{45}$ Thus far, results are modest, with the field still actively researching the most effective way to alter attentional bias to substance-related cues-and to translate these attempted changes into clinical outcomes. ${ }^{46}$ The underwhelming clinical results underscore the entrenched nature of attentional bias to drug-related cues and their potential importance as a treatment target.

\section{Response Inhibition}

Loss of control over drug use is a key feature of addiction. ${ }^{4}$ Inhibitory control refers generally to the ability to suppress or counter responses-whether these responses are behaviors, thoughts, or motivational states. In addiction, impairments in inhibitory control may account for the fundamental difficulty in resisting the motivational "pull" of drugs, thus increasing the vulnerability to relapse. ${ }^{47,48}$ Poor inhibitory control may also account for several behavioral patterns that are common in substance use disorders, including increased impulsivity, ${ }^{49-51}$ increased sensation seeking, ${ }^{52}$ increased risk-taking for rewards, ${ }^{53,54}$ and poor decision-making (e.g., choosing small immediate rewards over delayed, larger rewards), ${ }^{55}$ discussed in more detail later. Neuropsychological and neuroimaging studies have localized inhibitory control circuitry in the $\mathrm{PFC}^{56}$; these circuits normally function in a top-down way to govern downstream motivational systems for drugs and natural rewards. ${ }^{47,57,58}$ This ability to inhibit impulses toward reward, to delay gratification, shows significant variability across individuals, and these differences can be detected very early in development, ${ }^{59}$ well before any drug exposure. Importantly, however, chronic exposure to some drug classes (especially stimulants) can actually erode the "braking ability" of the brain. ${ }^{60-62}$

The most common tasks for probing inhibitory control feature instructed attempts to inhibit a simple prepotent motor response. The "go/no-go" task presents a stream of "go" stimuli (often simple letters or shapes) that require a rapid button press, while infrequent "no-go" stimuli require "withholding" the button press. ${ }^{63}$ Accidentally pressing the button to a no-go target indicates a failure to inhibit. "Stop-signal" tasks require the inhibition of a motor response that is already underway, ${ }^{64,65}$ with reaction time (to stop) as the primary measure. Though these motor tasks are simpler than real-world situations requiring inhibition (e.g., resisting drug use), poor performance in these tasks is generally well correlated with higher-order failures of inhibition, such as drug relapse. ${ }^{66}$ In an attempt to capture real-world inhibition struggles, some tasks have used valenced stimuli as signals, requiring inhibition of approach to "positive" stimuli, ${ }^{67,68}$ and responding in a valenced go/no-go task was actually better correlated with clinical symptom severity (impulsivity in attention-deficit hyperactivity disorder) ${ }^{68}$ than responding in standard non-valenced go/no-go tasks.

Laboratory models that require participants to attempt inhibition of craving to drug video cues ${ }^{69}$ provide a close parallel to the real-world challenges faced by patients in recovery. These paradigms reveal that patients with a better outcome prognosis demonstrate good communication (functional connection) between cortical inhibitory regions (i.e., the dorsal anterior cingulate) and downstream motivational circuitry (e.g., the amygdala), whereas patients with a poor outcome prognosis lack this critical connection. In general, the neuroimaging literature has identified poorer recruitment (hypoactivity) of top-down inhibitory regions in drug users versus controls during simple laboratory tasks of inhibition; this is especially marked in stimulant users. ${ }^{47,48,56,58,70-72}$ Intriguingly, cocaine patients who achieve extended abstinence actually demonstrate a heightened ability to recruit cognitive control regions. ${ }^{73}$ This could suggest either that recovery of inhibitory ability improves with (cocaine) abstinence and/or that individuals with strong inhibitory ability are more likely to achieve extended abstinence. ${ }^{74}$ Longitudinal studies will be needed to address these possibilities.

Studies attempting to improve inhibitory function either with medications that target frontal circuitry ${ }^{64,65}$ or by direct neural stimulation (Transcranial Magnetic Stimulation or transcranial direct current stimulation) of inhibitory circuitry ${ }^{75,76}$ are still in the early stages. However, they offer continued encouragement that inhibition is a clinically meaningful intermediate phenotype for targeted interventions.

\section{Working Memory}

Baddeley defined working memory as a system for the temporary maintenance and manipulation of information, necessary for the performance of such complex cognitive activities as comprehension, learning, and reasoning. ${ }^{77}$ It is thought to include three subsystems: a phonological loop, concerned with verbal and acoustic information; a visuospatial sketchpad, concerned with visual information; and the central executive, a capacitylimited control system that allocates finite resources and actively manipulates them. ${ }^{78,79}$ 
Tasks that measure working memory (n-back, visuospatial, digit and word recall, verbal memory, etc.), have revealed cognitive deficits in individuals with a substance use disorder. ${ }^{10,80-85}$ Working memory impairments could be associated with chronic toxic effects of drug use, ${ }^{84}$ and lower executive cognitive ability has been found to increase susceptibility to problematic drug use. ${ }^{86}$ As such, working memory represents a therapeutic target in substance use disorders that could be potentially linked with functional outcomes. Retraining working memory may help to bolster the central executive subsystem of working memory, which may help other cognitive functioning. ${ }^{79}$ Thus, addiction researchers have begun to target working memory with the goal of improving cognitive control. For example, Bickel and colleagues used a program (e.g., verbal memory, recall of numbers and words) to train the working memory of individuals with stimulant use disorders. ${ }^{82}$ Those authors were able to show improvements of delay-discounting, but not working memory. Houben and colleagues used working memory training on individuals with alcohol use disorders and found both reduced alcohol use and improved working memory. ${ }^{87}$

Another rationale for targeting working memory relates to dopaminergic mechanisms, known to be central to addiction. ${ }^{88}$ Working memory capacity is dependent on dopaminergic mechanisms, ${ }^{89}$ and it has been shown that working memory training affects dopamine systems. ${ }^{90,91}$ When behavioral interventions are not fully effective, having pharmacological approaches could act as a facilitation tool. For example, there is accumulated evidence that working memory impairments might be compensated with psychoactive drugs, ${ }^{92-94}$ optimizing dopaminergic function in individuals with addiction. In turn, this may aid them in achieving long-sought functional restoration and support the goals of drug use reduction and abstinence.

\section{Decision-Making Systems}

Seemingly poor decision-making is a prominent feature of addiction, reflected in the continued use of drugs and alcohol in the face of negative consequences. ${ }^{4}$ This type of behavior may seem counterintuitive, but there are several theories that address why/how these "poor" choices continue to be made. Verdejo-García and Bechara's "somatic markers" theory ${ }^{95}$ states that individuals with addiction have reduced awareness of learned emotional warning signals from the body (interoception) that translates into risky decision-making and "myopia" for the future, similar to individuals with ventromedial PFC lesions. Similarly, Bickel and Marsch focus on cognitive impairment that leads to a discounting of larger, delayed rewards for a preferred smaller, more immediate reward. ${ }^{13}$ These poor decisions are thought to arise from an imbalance of top-down and bottom-up processing. Top-down processing involves deliberative decisions, which are flexible and sensitive to devaluation, but are slow and cognitively intensive. ${ }^{96}$ On the other hand, more automatic actions, such as habit-based and classically conditioned behaviors are fast but inflexible and insensitive to devaluation. ${ }^{96}$ Initially, decisions to use drugs and alcohol are more deliberate, but with continued use, these actions will transition into more automatic behaviors, eventually becoming compulsive. ${ }^{97}$ Contributing to this transition to more automatic decision-making is (learned) incentive salience, the tendency of drug-related cues to take on motivating properties. $^{22}$

Several tasks are used to measure aspects of decisionmaking systems. For example, delay-discounting tasks allow for the assessment of how well someone is able to delay immediate gratification for a higher-value reward later. ${ }^{13}$ Individuals with addiction tend to discount larger, delayed rewards more than healthy controls, and these higher rates of discounting larger, future rewards have been shown to be associated with disadvantageous behaviors, ${ }^{13}$ including drug use. Other tasks, such as the Iowa gambling task measure real-time decision-making, and people with addiction generally perform worse than controls; a subgroup of addicted individuals may lack the implicit interoceptive guidance toward a more advantageous strategy. ${ }^{98}$

Researchers have adapted several methods in an attempt to restore the balance of top-down and bottomup processing. For example, working memory training (as discussed earlier) seems to bolster the central executive subsystem, reducing discounting, ${ }^{82}$ improving working memory, ${ }^{87}$ and decreasing substance use. ${ }^{87}$ Recently, meditation has shown promise as a way to potentially improve executive control ${ }^{99}$ and to improve awareness of internal states (and the ability to label them), thus countering alexithymia ${ }^{100}$ and potentially improving interoception. Contingency management approaches may boost deliberative decision-making and help reduce automated drug-choice behaviors by making concrete non-drug rewards immediately available ${ }^{101}$ and contingent on a reduction in drug use. Contingency management approaches have good impact while the procedures are in place, ${ }^{102-104}$ with the transition to the broader real-world setting as the clinical challenge. Preclinical research has demonstrated that automatic behaviors are malleable (e.g., inactivating parts of the brain that underlie habit-based behaviors [e.g., dorsolateral striatum] reduces automatic actions and increases cognitive regulation by other brain areas [e.g., hippocampus]). ${ }^{105}$ In humans, devaluation of drug-related stimuli can reduce drug use behaviors, ${ }^{106}$ also pointing to the potential modification of decision-making with behavioral strategies. However, given the reflexive 
nature of automated decision processes-not just in addiction pathology, but in everyday decision-makingthe clinical impact of behavioral strategies is often modest and has encouraged the testing of additional approaches. Direct neurostimulation of cortical areas via transcranial magnetic stimulation offers a promising approach, as it has been shown to reduce craving 107,108 and delay discounting. ${ }^{109}$ Pharmacologic approaches to improve decision-making with "cognitive enhancers" also offer preliminary evidence that is promising. For example, modafinil (dopamine drug with potential abuse liability) improved delay discounting, ${ }^{110}$ and atomoxetine (non-dopamine drug without abuse liability) improved impaired executive function. ${ }^{111}$ Even though a clinical trial of atomoxetine in cocaine addiction was disappointing, ${ }^{112}$ there is an ongoing need for medications that can either reduce the implicit, automated processes in decision-making, bolster the deliberative processes, or both.

\section{Precognition}

Processes that are rapid and implicit and that even occur outside conscious awareness are important precursors and contributors to each of the classic executive cognitive domains reviewed here (attention, inhibition, working memory, and decision-making). In Figure 1, processes in the precognitive realm are shaded in blue, and can originate from appetitive or aversive motivational states. Though some of these may eventually be reflected in an explicit (shaded in green) cognition or decision, for example, "I will plan to buy drugs when I get paid tomorrow," others may shape drug-related feelings and behavior while remaining completely outside awareness.

In the domain of attention, the response to drug cues is fast, involuntary, and implicit - the product of powerful prior associative learning. The individual struggling with a substance use disorder does not need to consciously, deliberately focus attention on a drugrelated cue for it to have a motivating effect. ${ }^{19,116}$ Indeed, the riveted attention to a drug-related cue may occur even when successful task performance instead depends on a flexible shift of attention away from drug images. ${ }^{16,20}$ Precognitive processes also play a role in inhibition tasks. As previously detailed, these tasks typically instruct deliberate, explicit, conscious attempts to inhibit a "prepotent" (whether motor- or drug-related) response. However, the prepotency of the responses to be inhibited depends on their "near-automatic" nature. For example, motor prepotency results from a rapid series of button presses to a "go" signal, and a prepotent approach to drug stimuli is the near-automatic result of much prior learning. In the domain of working memory, an individual's ability to maintain and update information, to allocate cognitive resources, generally happens implicitly, from moment to moment, without a conscious focus. Experimental tasks that probe working memory may instruct the participant to intentionally recall an item earlier in a string (e.g., the n-back test), but in real life, this kind of memory occurs in an ongoing precognitive way, without explicit awareness and without prompting. The realm of decision-making especially highlights the "competition" between fast, implicit, precognitive responses (e.g., the approach response to immediate reward and discounting of delayed future rewards) versus slower, deliberative responses (e.g., taking the future into account, including any future negative consequences of the approach to the drug reward). The human challenge of balancing fast, implicit, precognitive decision processes against slow, deliberative processes has been recognized across history and is the foundation for several "dual-process" models ${ }^{113}$ of decision-making.

Given the broad contribution of precognitive processes, what are the implications for addiction treatment? As conventional cognitive behavioral treatments are directed to faulty explicit cognitions, these interventions may not affect implicit processes. That the high rates of relapse that are common for substance use disorders have remained relatively unchanged across the decades may reflect (at least in part) a difficulty in addressing the precognitive domain. As noted earlier, from the few available studies, behavioral attempts to change the attentional bias to drug cues have met with only modest success, ${ }^{41}$ and studies using working memory training are still in the early stages. ${ }^{82,87}$ Encouragingly, pharmacologic interventions might be well suited to the precognitive domain. As an example, a recent study demonstrated that the noradrenaline uptake inhibitor atomoxetine was able to reduce attentional bias to cocaine cues ${ }^{114}$ (though a clinical trial did not demonstrate benefit ${ }^{112}$ ), and the opioid antagonist naltrexone was shown to improve the recruitment of modulatory circuitry (lateral orbitofrontal cortex) in a "now-later" decision-making task. ${ }^{115}$ The $\mathrm{GABA}_{\mathrm{B}}$ agonist baclofen, known to reduce dopamine release, ${ }^{116}$ was shown to blunt the mesolimbic activation triggered by $33 \mathrm{msec}$ cocaine cues presented outside conscious awareness. ${ }^{117}$ The ability of brief "unseen" drug cues to trigger motivational circuitry ${ }^{118,119}$ offers a paradigm for screening the ability of candidate medications to impact precognition, complementing conventional self-reports of conscious motivational ("craving") states.

A construct with a special relationship to the precognition domain is interoception, the organism's sense of its own internal state(s). ${ }^{120-122}$ Broadly, interoception is based on bodily sensations reflecting a change in internal state (e.g., hunger, thirst, temperature) or autonomic visceral responses (e.g., heart 
palpitations, sweating, gut motility) arising in response to powerful external stimuli (e.g., pain, threat, sexual opportunity, even the anticipated reward from drugs of abuse). Importantly, these varied bodily sensations can also become attached, through learning, to previously neutral cues, enabling the cues to guide the organism away from danger, or toward reward. ${ }^{121,123,124}$

With these links both to danger and to reward, it is understandable that interoception has been featured in human addiction models. Bechara and colleagues ${ }^{98}$ hypothesized that impaired interoception (aka "somatic markers") for negative stimuli (e.g., the negative consequences of drug choice) could contribute to relapse. On the other hand, heightened interoception for the positive (appetitive) arousal triggered by drug reminder cues can also be a relapse vulnerability, ${ }^{57,118,125}$ fueling the "incentive salience" of these cues. Whether for aversive or appetitive states, the anterior insula has been strongly implicated in interoceptive processing and emotional awareness. ${ }^{119}$ Supporting the clinical significance of the insula in interoception, an attenuated response in the insula during decision-making predicted relapse in methamphetamine users. ${ }^{126,127}$ Intriguingly, cigarette smokers who sustained injury to the insula-presumably impacting both appetitive and aversive interoceptionslost the motivation to smoke (they "simply forgot to crave a cigarette"). ${ }^{128,129}$ As in these examples, interoceptions often have their origins in the precognitive domain and can influence addiction-relevant decision-making, even when-perhaps especially when-the individual has limited self-awareness. Indeed, some therapeutic approaches in substance use (and other disorders) are geared to improving the individuals' conscious, explicit awareness of their internal states as a step toward greater cognitive control. Novel treatments targeting the insula with real-time neuro-feedback ${ }^{130-132}$ or direct brain stimulation $^{133}$ underscore the promise of interoceptive processes as a meaningful therapeutic target in substance use disorders.

\section{Social Cognition}

\section{Metacognition}

We humans have the ability to look inside ourselves, which allows us to understand the relationship between ourselves and others, to monitor our own thought processes, and to control thoughts, all of these activities are related to metacognition. However, impairments of metacognition can have negative consequences on decision-making, such as being overconfident about a poor decision or lacking confidence in a better decision. ${ }^{134,135}$

The scope of metacognitive impairment in substance use disorders has not been well researched, despite it being a striking and critical feature of the addiction phenotype. For example, many researchers report a dissociation between self-report and behavior, low treatment compliance, frequent relapse, impaired psychosocial functioning, and a lack of perception that treatment is actually needed. In 2015, more than 21 million individuals (12 or older) were classified as needing treatment for a substance use disorder. Just more than $10 \%$ actually received treatment for a disorder; however, among the rest ( 19 million), only about $5 \%$ perceived the need for treatment. ${ }^{136}$ Goldstein and colleagues have reported that this impairment is reflective of an existing dysfunction in the neural circuitry. ${ }^{137}$ Neurologically, it is thought that mechanisms of metacognition reside in frontal structures, such as the rostral anterior cingulate cortex, ${ }^{138,139}$ and that dysfunction of ventrolateral PFC may be an important contributor to the insight impairment. ${ }^{140}$

Metacognitive deficits can be thought of as impairments of insight, shown to be a common feature in addiction. ${ }^{141,142}$ In the substance use disorder literature, lack of insight has sometimes been conflated with "denial." However, the two are distinct. Denial implies a refusal or contradiction of something of which the person is aware, while lack of insight involves a lack of awareness of something present in the individual. Some researchers in mental health disorders separate clinical insight, which is a construct composed of awareness of illness, recognizing the need for treatment, and relabeling symptoms, and impaired general insight, which is connected with poorer treatment outcome, an inability to perceive the severity of illness, poor psychosocial functioning, higher relapse, and low self-esteem. ${ }^{143}$ If individuals with substance use disorders are not able to assess the level of severity of their impairments, or in some cases are not even aware that they have a disorder, this may help explain the lack of perceived need for treatment. It is worth noting that even after recognizing the need for help and seeking treatment, patients may still struggle and relapse. Thus self-awareness is important but maybe not sufficient for recovery.

It has also been noted that addiction involves deficits of self-awareness and behavioral control similar to what is seen in other neuropsychiatric disorders (e.g., mood, psychotic, and neurological disorders). ${ }^{137,144,145}$ Research has suggested that this insight deficit is reflected in one of the key attributes of substance use disorder defined in the DSM classification: drugs are used despite negative consequences. Self-awareness deficits and metacognitive impairments persist even in remitted drug users, revealed, for example, by remitted users' poor association between self-reported confidence in performance and actual performance on a visuo-perceptual accuracy task. $^{146}$

We are aware of at least two methods to address the insight deficit and bolster metacognitive abilities. One is 
metacognitive therapy (MCT), which was first developed to address impairments of cognition that occur in several stress-related disorders such as depression, anxiety, PTSD, and obsessive-compulsive disorder. ${ }^{14-152}$ Metacognitive therapy has been described a hybrid of cognitive-behavioral therapy and psychoeducation ${ }^{153,154}$ and has been shown to be efficacious in reducing schizophrenia-related anxiety and depression symptoms. ${ }^{155,156}$ Another method is metacognitive strategy instruction, which was found to be helpful for those with below-average decision-making performance but not for those with average or above-average decision-making performance. ${ }^{136}$ Recent metacognitive models have been directed toward addiction, ${ }^{148,157}$ but formal clinical trials in substance use disorders using MCT or metacognitive strategy instruction are not yet available.

\section{Theory of mind}

Within the social cognition domain of addiction, there exists a relatively understudied cognitive construct called theory of mind (ToM). ToM is described as the cognitive capacity to have an implicit assumption about the behavior and intentions of others, as driven by their desires, attitudes, and beliefs. ${ }^{158-160}$ The capacity for social insight in humans is dependent upon this process. ToM mainly consists of two subtypes: "cognitive" ToM for attribution of beliefs and intentions and "affective" ToM for attribution of emotions. ${ }^{161}$ Studies of ToM and its impairment in mental disorders traditionally were investigated in developmental psychology in children ${ }^{162,163}$ but then were applied to disorders such as autism, schizophrenia, and personality and neurological disorders, in which impairments in social cognition are very central to their phenotypical presentation. ${ }^{159,164-168}$ In psychotic spectrum disorder and schizophrenia, for example, social cognition impairment has been strongly linked with functional outcome. ${ }^{169-171}$ In addition, evidence has accumulated that ToM mediates the pathway from neurocognition to functional outcome in young adults with recent onsets of mood, anxiety, and personality disorders, ${ }^{172}$ and in people with bipolar disorders, ToM deficits could be viewed as a core deficit feature, which is independent from other symptoms and patient characteristics. ${ }^{173}$ For substance use disorders, recent meta-analysis of social cognition in alcohol use disorder showed a significant deficit in emotion recognition and cognitive ToM. ${ }^{174}$ ToM impairments were also found in individuals with cocaine use disorders ${ }^{175}$ but not recreational cocaine ${ }^{176}$ or cannabis users. ${ }^{177,178}$ More sensitive neurophysiological measures of brain activity (e.g., fMRI), may be able to further identify differences in the ToM neural network activation of individuals using substances recreationally and those with clinically diagnosable substance use disorders.
In regard to assessment tasks, the "Reading the Mind in the Eyes" task has been used to examine affective ToM. ${ }^{179}$ The "Theory of Mind Stories" task has been used to examine second-order understanding of false beliefs, ${ }^{180}$ and there are other tasks in development (e.g., using a virtual reality paradigm ${ }^{181}$ ). Interventions that have shown to bring positive change in affective ToM are possible, including psychodynamic art therapy, which was previously shown to reduce symptoms in patients with schizophrenia. ${ }^{182}$

Social cognition impairments are present transdiagnostically across neuropsychiatric disorders, including substance use disorders. However, more research in social cognition deficits for substance use disorders is needed to potentially add treatment options that may translate into long-sought functional gains.

\section{Conclusion}

This review presents an overview of cognitive impairments in drug and alcohol use disorders. Cognitive impairments are addressed as a continuum, with one end representing the more precognitive processes and the other end extending to higher levels, such as social cognition; in between are the familiar cognitive executive domains (Figure 1). In this review of the cognitive executive domain, we found that most of the research has been focused on characterizing patients versus controls and documenting differences in each of these domains (e.g., attention, response inhibition, working memory, decision-making systems). For each of these domains, there is also an emerging body of evidence for its status as an intermediate phenotype and potential target for intervention. However, the translation from intermediate phenotype to clinical outcome is still in the early stages. Novel treatments (e.g., neurostimulation, pharmacologic "rebalancing") offer promise for the next phase of translational research, inclusive of cognitive deficits in substance use disorders. We described a "cognitive continuum," for which the extremes (precognition, social cognition) have been less studied. We suggest the unique features of these domains (e.g., impaired interoception, metacognitive deficits, impaired insight into illness) offer viable therapeutic targets that may both require and stimulate entirely new interventions.

It is important to recognize that, in cross-sectional research, it is difficult to determine whether drug use was predated, predisposed, exacerbated, or caused entirely by cognitive impairments. New longitudinal studies in developmental cohorts ${ }^{183}$ before drug exposure will help to determine the relative contribution of individual variables (e.g., genetics, epigenetics, adversity) versus drug variables (e.g., type of drug, dose, exposure, frequency) to the observed impairments. This information is critical both for selecting therapeutic 
targets and for shaping therapeutic expectations (e.g., restoring function vs. remedial biological supports).

Finally, worth noting, the phenotypical features stemming from both the familiar and extended cognitive domains are not confined to addiction but are both dimensional and transdiagnostic and relevant for other neuropsychiatric disorders and conditions (a focus of RDoC). Thus, therapeutic discoveries in the addiction arena might be expected to have direct relevance for other major psychiatric disorders sharing the dimensions of these cognitive impairments. ${ }^{184}$ Research in these domains will also be helpful in empirically determining the unique contributions of intermediate phenotypes versus an overall psychopathology (e.g., factor " $\mathrm{p}^{\text {"185 }}$ ) in guiding treatments and predicting clinical outcomes.

\section{Acknowledgments}

The authors wish to acknowledge Anna Rose Childress, $\mathrm{PhD}$, for input on precognition and Figure 1, and to thank Kimberly Young, PhD, and Stefanie Darnley, BS, for professional assistance in preparing the article for submission. Professional research effort for Paul S. Regier was supported by a National Institute on Drug Abuse (NIDA) T32 Translational Addiction Research Training program (Childress, Co-PI); professional effort for Dr. Childress, Dr. Young, and Ms. Darnley was supported in part by a NIDA U54 Cocaine Cooperative Medication Development Center (U54DA039002, Kampman PI) and by NIDA R01 DA039215 (Childress, PI).

\section{Disclosures}

Tatiana Ramey and Paul Regier have nothing to disclose.

\section{REFERENCES:}

1. Gould TJ. Addiction and cognition. Addict Sci Clin Pract. 2010; 5(2): 4-14.

2. Saha TD, Chou SP, Grant BF. Toward an alcohol use disorder continuum using item response theory: results from the National Epidemiologic Survey on Alcohol and Related Conditions. Psychol Med. 2006; 36(7): 931-941.

3. Patrono E, Gasbarri A, Tomaz C, Nishijo H. Transitionality in addiction: a "temporal continuum" hypotheses involving the aberrant motivation, the hedonic dysregulation, and the aberrant learning. Med Hypotheses. 2016; 93: 62-70.

4. American Psychiatric Association. Diagnostic and Statistical Manual of Mental Disorders, 5th ed. Arlington, VA: American Psychiatric Publishing; 2013.

5. Koob GF, Volkow ND. Neurocircuitry of addiction. Neuropsychopharmacology 2010; 35(1): 217-238.

6. Insel T, Cuthbert B, Garvey M, et al. Research domain criteria (RDoC): toward a new classification framework for research on mental disorders. Am J Psychiatry. 2010; 167(7): 748-751.

7. O'Donnell P, Ehlers MD. Opportunities for new drug development in psychiatry: a glass half-full. JAMA Psychiatry. 2015; 72(11): 1067-1068.
8. Kwako LE, Momenan R, Litten RZ, Koob GF, Goldman D. Addictions neuroclinical assessment: a neuroscience-based framework for addictive disorders. Biol Psychiatry. 2016; 80(3): 179-189.

9. Koob GF. Neurobiological substrates for the dark side of compulsivity in addiction. Neuropharmacology. 2009; 56(suppl 1): 18-31.

10. Goldstein RZ, Volkow ND. Dysfunction of the prefrontal cortex in addiction: neuroimaging findings and clinical implications. Nat Rev Neurosci. 2011; 12(11): 652-669.

11. Goldstein RZ, Volkow ND, Wang GJ, Fowler JS, Rajaram S. Addiction changes orbitofrontal gyrus function: involvement in response inhibition. Neuroreport. 2001; 12(11): 2595-2599.

12. Monterosso J, Ainslie G. Beyond discounting: possible experimental models of impulse control. Psychopharmacology. 1999; 146(4): 339-347.

13. Bickel WK, Marsch LA. Toward a behavioral economic understanding of drug dependence: delay discounting processes. Addiction (Abingdon, England). 2001; 96(1): 73-86.

14. Madden GJ, Petry NM, Badger GJ, Bickel WK. Impulsive and selfcontrol choices in opioid-dependent patients and non-drug-using control participants: drug and monetary rewards. Exp Clin Psychopharmacol. 1997; 5(3): 256-262.

15. Sofuoglu M, DeVito EE, Waters AJ, Carroll KM. Cognitive function as a trans-diagnostic treatment target in stimulant use disorders. J Dual DIagn. 2016; 12(1): 90-106.

16. Field M, Mogg K, Bradley BP. Attention to drug-related cues in drug abuse and addiction: component processes. In: R. W. Wiers \& A. W. Stacy (Eds.), Handbook of Implicit Cognition and Addiction. Thousand Oaks, CA: Sage; 2006: 151-164.

17. Roberts W, Fillmore MT. Attentional bias to alcohol-related stimuli as an indicator of changes in motivation to drink. Psychol Addictive Behav. 2015; 29(1): 63-70.

18. Anderson BA. What is abnormal about addiction-related attentional biases? Drug Alcohol Depend. 2016; 167: 8-14.

19. Wetherill RR, Childress AR, Jagannathan K, et al. Neural responses to subliminally presented cannabis and other emotionally evocative cues in cannabis-dependent individuals. Psychopharmacology. 2014; 231(7): 1397-1407.

20. Field M, Cox WM. Attentional bias in addictive behaviors: a review of its development, causes, and consequences. Drug Alcohol Depend. 2008; 97(1-2): 1-20.

21. Stewart J, de Wit H, Eikelboom R. Role of unconditioned and conditioned drug effects in the self-administration of opiates and stimulants. Psychol Rev. 1984; 91(2): 251-268.

22. Robinson TE, Berridge KC. Incentive-sensitization and addiction. Addiction (Abingdon, England). 2001; 96(1): 103-114.

23. Baker TB, Piper ME, McCarthy DE, Majeskie MR, Fiore MC. Addiction motivation reformulated: an affective processing model of negative reinforcement. Psychol Rev. 2004; 111(1): 33-51.

24. Leeman RF, Robinson CD, Waters AJ, Sofuoglu M. A critical review of the literature on attentional bias in cocaine use disorder and suggestions for future research. Exp Clin Psychopharmacol . 2014; 22(6): 469-483.

25. Cox WM, Fadardi JS, Pothos EM. The addiction-Stroop test: theoretical considerations and procedural recommendations. Psychol Bull. 2006; 132(3): 443.

26. Froeliger B, Modlin L, Wang L, Kozink RV, McClernon FJ. Nicotine withdrawal modulates frontal brain function during an affective Stroop task. Psychopharmacology. 2012; 220(4) 707-718.

27. Munafò M, Mogg K, Roberts S, Bradley BP, Murphy M. Selective processing of smoking-related cues in current smokers, ex-smokers and never-smokers on the modified Stroop task. J Psychopharmacol. 2003; 17(3): 310-316. 
28. Rzetelny A, Gilbert DG, Hammersley J, Radtke R, Rabinovich NE, Small SL. Nicotine decreases attentional bias to negative-affectrelated Stroop words among smokers. Nicotine Tob Res. 2008; 10(6): 1029-1036.

29. Pike E, Stoops WW, Fillmore MT, Rush CR. Drug-related stimuli impair inhibitory control in cocaine abusers. Drug Alcohol Depend. 2013 ; 133(2): 768-771.

30. Waters AJ, Marhe R, Franken IH. Attentional bias to drug cues is elevated before and during temptations to use heroin and cocaine. Psychopharmacology. 2012; 219(3): 909-921.

31. Waters AJ, Sayette MA, Franken IH, Schwartz JE. Generalizability of carry-over effects in the emotional Stroop task. Behav Res Ther. $2005 ;$ 43(6): 715-732.

32. Fadardi JS, Ziaee SS. A comparative study of drug-related attentional bias: evidence from Iran. Exp Clin Psychopharmacol. 2010; 18(6): 539-545

33. Franken IH, Kroon LY, Wiers RW, Jansen A. Selective cognitive processing of drug cues in heroin dependence. J Psychopharmacol. 2000; 14(4): 395-400.

34. Field M. Cannabis "dependence" and attentional bias for cannabisrelated words. Behav Pharmacol. 2005; 16(5-6): 473-476.

35. Cousijn J, Watson P, Koenders L, Vingerhoets WAM, Goudriaan AE, Wiers RW. Cannabis dependence, cognitive control and attentional bias for cannabis words. Addict Behav. 2013; 38(12): 2825-2832.

36. Snelleman M, Schoenmakers TM, van de Mheen D. Attentional bias and approach/avoidance tendencies do not predict relapse or time to relapse in alcohol dependency. Alcohol Clin Exp Res. 2015; 39(9): 1734-1739.

37. Mogg K, Bradley BP, Field M, De Houwer J. Eye movements to smoking-related pictures in smokers: relationship between attentional biases and implicit and explicit measures of stimulus valence. Addiction (Abingdon, England). 2003; 98(6): 825-836.

38. Field M, Mogg K, Bradley BP. Eye movements to smoking-related cues: effects of nicotine deprivation. Psychopharmacology. 2004; 173(1-2): 116-123.

39. Field M, Mogg K, Bradley BP. Attention to drug-related cues in drug abuse and addiction: component processes. In: R. W. Wiers \& A. W. Stacy (Eds.), Handbook of Implicit Cognition and Addiction. Thousand Oaks, CA: Sage; 2006: 39-41.

40. Jones BT, Bruce G, Livingstone S, Reed E. Alcohol-related attentional bias in problem drinkers with the flicker change blindness paradigm. Psychol Addict Behav. 2006; 20(2): 171.

41. Wiers RW, Eberl C, Rinck M, Becker ES, Lindenmeyer J. Retraining automatic action tendencies changes alcoholic patients' approach bias for alcohol and improves treatment outcome. Psychol Sci. 2011; 22(4): 490-497.

42. Field M, Duka T, Eastwood B, Child R, Santarcangelo M, Gayton M. Experimental manipulation of attentional biases in heavy drinkers: do the effects generalise? Psychopharmacology. 2007; 192(4): 593-608.

43. Schoenmakers T, Wiers RW, Jones BT, Bruce G, Jansen ATM. Attentional re-training decreases attentional bias in heavy drinkers without generalization. Addiction (Abingdon, England). 2007; 102(3): 399-405.

44. Schoenmakers TM, de Bruin M, Lux IFM, Goertz AG, Van Kerkhof DHAT, Wiers RW. Clinical effectiveness of attentional bias modification training in abstinent alcoholic patients. Drug Alcohol Depend. 2010; 109(1-3): 30-36.

45. Mayer AR, Wilcox CE, Dodd AB, et al. The efficacy of attention bias modification therapy in cocaine use disorders. Am J Drug Alcohol Abuse. 2016; 42(4): 459-468.

46. Wiers RW, Gladwin TE, Hofmann W, Salemink E, Ridderinkhof KR. Cognitive Bias modification and cognitive control training in addiction and related psychopathology: mechanisms, clinical perspectives, and ways forward. Clin Psychol Sci. 2013; 1(2): 192-212.

47. Smith JL, Mattick RP, Jamadar SD, Iredale JM. Deficits in behavioural inhibition in substance abuse and addiction: a metaanalysis. Drug Alcohol Depend. 2014; 145 : 1-33.

48. Luijten M, Field M, Franken IH. Pharmacological interventions to modulate attentional bias in addiction. CNS Spectr. 2014; 19(3): 239-246.

49. Bornovalova MA, Daughters SB, Hernandez GD, Richards JB, Lejuez CW. Differences in impulsivity and risk-taking propensity between primary users of crack cocaine and primary users of heroin in a residential substance-use program. Exp Clin Psychopharmacol. 2005; 13(4): 311-318.

50. Bornovalova MA, Lejuez CW, Daughters SB, Zachary Rosenthal M, Lynch TR. Impulsivity as a common process across borderline personality and substance use disorders. Clinical Psychol Rev. 2005; 25(6): 790-812.

51. Verdejo-Garcia A, Rivas-Perez C, Vilar-Lopez R, Perez-Garcia M. Strategic self-regulation, decision-making and emotion processing in poly-substance abusers in their first year of abstinence. Drug Alcohol Depend. 2007; 86(2-3): 139-146.

52. Patkar AA, Murray HW, Mannelli P, Gottheil E, Weinstein SP, Vergare MJ. Pre-treatment measures of impulsivity, aggression and sensation seeking are associated with treatment outcome for African-American cocaine-dependent patients. J Addict Dis. 2004; 23(2): 109-122.

53. Lejuez CW, Aklin WM, Jones HA, et al. The Balloon Analogue Risk Task (BART) differentiates smokers and nonsmokers. Exp Clin Psychopharmacol. 2003; 11(1): 26-33.

54. Lejuez CW, Aklin WM, Zvolensky MJ, Pedulla CM. Evaluation of the Balloon Analogue Risk Task (BART) as a predictor of adolescent real-world risk-taking behaviours. J Adolesc. 2003; 26(4): 475-479.

55. Bechara A, Dolan S, Denburg N, Hindes A, Anderson SW, Nathan PE. Decision-making deficits, linked to a dysfunctional ventromedial prefrontal cortex, revealed in alcohol and stimulant abusers. Neuropsychologia. 2001; 39(4): 376-389.

56. Garavan H, Hester R, Murphy K, Fassbender C, Kelly C. Individual differences in the functional neuroanatomy of inhibitory control. Brain Res. 2006; 1105(1): 130-142.

57. Childress AR, Mozley PD, McElgin W, Fitzgerald J, Reivich M, O'Brien CP. Limbic activation during cue-induced cocaine craving. Am J Psychiatry. 1999; 156(1): 11-18.

58. Kaufman JN, Ross TJ, Stein EA, Garavan H. Cingulate hypoactivity in cocaine users during a GO-NOGO task as revealed by eventrelated functional magnetic resonance imaging. J Neurosci. 2003; 23(21): 7839-7843.

59. Mischel W, Shoda Y, Rodriguez MI. Delay of gratification in children. Science. 1989; 244(4907): 933-938.

60. Goldstein RZ, Volkow ND. Drug addiction and its underlying neurobiological basis: neuroimaging evidence for the involvement of the frontal cortex. Am J Psychiatry. 2002; 159 (10): 1642-1652.

61. Bjork JM, Momenan R, Hommer DW. Delay discounting correlates with proportional lateral frontal cortex volumes. Biol Psychiatry. $2009 ; \mathbf{6 5}(8)$ : 710-713.

62. Garavan H, Kaufman JN, Hester R. Acute effects of cocaine on the neurobiology of cognitive control. Philos Trans R Soc Lond B Biol Sci. 2008; 363(1507): 3267-3276.

63. Horn NR, Dolan M, Elliott R, Deakin JF, Woodruff PW. Response inhibition and impulsivity: an fMRI study. Neuropsychologia. $2003 ;$ 41(14): 1959-1966.

64. Robbins TW. Shifting and stopping: fronto-striatal substrates, neurochemical modulation and clinical implications. Philos Trans R Soc Lond B Biol Sci. 2007; 362(1481): 917-932. 
65. Dalley JW, Robbins TW. Fractionating impulsivity: neuropsychiatric implications. Nat Rev Neurosci. 2017; 18(3): 158-171.

66. Moeller SJ, Paulus MP. Toward biomarkers of the addicted human brain: using neuroimaging to predict relapse and sustained abstinence in substance use disorder. Prog Neuropsychopharmaco Biol Psychiatry. 2018; 80(Pt B): 143-154.

67. Casey BJ, Somerville LH, Gotlib IH, et al. Behavioral and neural correlates of delay of gratification 40 years later. Proc Natl Acad Sci USA. 2011; 108(36): 14998-15003.

68. Goldman M, Ehrman RN, Suh JJ, et al. Brief report: "Spiders-No, Puppies-Go," introducing a novel Go NoGo task tested in inner city adolescents at risk for poor impulse control. J Adolesc. 2015; 38: $45-48$.

69. Lam SC, Wang Z, Li Y, et al. Wavelet-transformed temporal cerebral blood flow signals during attempted inhibition of cueinduced cocaine craving distinguish prognostic phenotypes. Drug Alcohol Depend. $2013 ;$ 128(1-2): 140-147.

70. Spechler PA, Chaarani B, Hudson KE, Potter A, Foxe JJ, Garavan $H$. Response inhibition and addiction medicine: from use to abstinence. Prog Brain Res. 2016; 223: 143-164.

71. Garavan H, Ross TJ, Stein EA. Right hemispheric dominance of inhibitory control: an event-related functional MRI study. Proc Natl Acad Sci USA. 1999; 96(14): 8301-8306.

72. Luo X, Zhang S, Hu S, et al. Error processing and gender-shared and -specific neural predictors of relapse in cocaine dependence. Brain. 2013; 136(4): 1231-1244.

73. Connolly CG, Foxe JJ, Nierenberg J, Shpaner M, Garavan H. The neurobiology of cognitive control in successful cocaine abstinence. Drug Alcohol Depend. 2012; 121(1-2): 45-53.

74. Bell RP, Foxe JJ, Ross LA, Garavan H. Intact inhibitory control processes in abstinent drug abusers (I): a functional neuroimaging study in former cocaine addicts. Neuropharmacology. 2013; 82 143-150.

75. Jacobson L, Javitt DC, Lavidor M. Activation of inhibition: diminishing impulsive behavior by direct current stimulation over the inferior frontal gyrus. J Cogn Neurosci. 2011; 23(11): 3380-3387.

76. Dunlop K, Hanlon CA, Downar J. Noninvasive brain stimulation treatments for addiction and major depression. Ann NY Acad Sci. 2017; 1394(1): 31-54

77. Baddeley A. Working memory: the interface between memory and cognition. J Cogn Neurosci. 1992; 4(3): 281-288.

78. Baddeley AD, Hitch G. Working Memory. In: Bower GH, ed. Psychology of Learning and Motivation. Vol 8. Oxford, UK Academic Press; 1974: 47-89.

79. Baddeley A. Working memory and language: an overview. $J$ Commun Disord. 2003; 36(3): 189-208.

80. Bechara A, Martin EM. Impaired decision making related to working memory deficits in individuals with substance addictions. Neuropsychology. 2004; 18(1): 152-162.

81. Tomasi D, Goldstein RZ, Telang F, et al. Widespread disruption in brain activation patterns to a working memory task during cocaine abstinence. Brain Res. 2007; 1171: 83-92.

82. Bickel WK, Yi R, Landes RD, Hill PF, Baxter C. Remember the future: working memory training decreases delay discounting among stimulant addicts. Biol Psychiatry. 2011; 69(3): 260-265.

83. Patterson F, Jepson C, Loughead J, et al. Working memory deficit predict short-term smoking resumption following brief abstinence. Drug Alcohol Depend. 2010; 106(1): 61.

84. Yan W-S, Li Y-H, Xiao L, Zhu N, Bechara A, Sui N. Working memory and affective decision-making in addiction: a neurocognitive comparison between heroin addicts, pathological gamblers and healthy controls. Drug Alcohol Depend. 2014; 134: 194-200.
85. Goldstein RZ, Leskovjan AC, Hoff AL, et al. Severity of neuropsychological impairment in cocaine and alcohol addiction: association with metabolism in the prefrontal cortex. Neuropsychologia. 2004; 42(11): 1447-1458.

86. Hester R, Lubman DI, Yücel M. The role of executive control in human drug addiction. Curr Top Behav Neurosci. 2010; 3: 301-318.

87. Houben K, Wiers RW, Jansen A. Getting a grip on drinking behavior: training working memory to reduce alcohol abuse. Psychol Sci. 2011; 22(7): 968-975.

88. Volkow ND, Fowler JS, Wang GJ, Baler R, Telang F. Imaging dopamine's role in drug abuse and addiction. Neuropharmacology. 2009; 56(suppl 1): 3-8.

89. Cohen JD, Braver TS, Brown JW. Computational perspectives on dopamine function in prefrontal cortex. Curr Opin Neurobiol. 2002; 12(2): 223-229.

90. McNab F, Varrone A, Farde L, et al. Changes in cortical dopamine D1 receptor binding associated with cognitive training. Science. 2009; 323(5915): 800-802.

91. Backman L, Nyberg L, Soveri A, et al. Effects of workingmemory training on striatal dopamine release. Science. 2011 333(6043): 718.

92. Sofuoglu M, DeVito EE, Waters AJ, Carroll KM. Cognitive enhancement as a treatment for drug addictions. Neuropharmacology. 2013; 64: 452-463.

93. Rosell DR, Zaluda LC, McClure MM, et al. Effects of the $\mathrm{D}_{1}$ dopamine receptor agonist dihydrexidine (DAR-0100A) on working memory in schizotypal personality disorder. Neuropsychopharmacology. 2015; 40(2): 446-453.

94. Joyce JN, Millan MJ. Dopamine D3 receptor antagonists as therapeutic agents. Drug Discov Today. 2005; 10(13): 917-925.

95. Verdejo-García A, Bechara A. A somatic marker theory of addiction. Neuropharmacology. 2009; 56: 48-62.

96. van der Meer M, Kurth-Nelson Z, Redish AD. Information processing in decision-making systems. Neuroscientist. 2012; 18 (4): 342-359.

97. Everitt BJ, Robbins TW. From the ventral to the dorsal striatum: devolving views of their roles in drug addiction. Neurosci Biobehav Rev. 2013; 37(9 Pt A): 1946-1954.

98. Bechara A, Damasio H, Tranel D, Damasio AR. Deciding advantageously before knowing the advantageous strategy. Science. 1997; 275(5304): 1293-1295.

99. Teper R, Inzlicht M. Meditation, mindfulness and executive control: the importance of emotional acceptance and brain-based performance monitoring. Soc Cogn Affect Neurosci. 2013; 8(1): 8592

100. Baer RA, Smith GT, Hopkins J, Krietemeyer J, Toney L. Using selfreport assessment methods to explore facets of mindfulness. Assessment. 2006; 13(1): 27-45.

101. Regier PS, Redish AD. Contingency management and deliberative decision-making processes. Front Psychiatry. 2015; 6: 76

102. Stitzer M, Bigelow G. Contingency management in a methadone maintenance program: availability of reinforcers. Int J Addict. 1978; 13(5): 737-746

103. Higgins ST, Budney AJ, Bickel WK, Foerg FE, Donham R, Badger GJ. Incentives improve outcome in outpatient behavioral treatment of cocaine dependence. Arch Gen Psychiatry. 1994; 51(7): 568-576.

104. Petry NM, Martin B, Finocche C. Contingency management in group treatment: a demonstration project in an HIV dropin center. J Subst Abuse Treat. 2001; 21(2): 89-96.

105. Packard MG, McGaugh JL. Inactivation of hippocampus or caudate nucleus with lidocaine differentially affects expression of place and response learning. Neurobiol Learn Mem. 1996; 65(1): 65-72.

106. Houben K, Havermans RC, Nederkoorn C, Jansen A. Beer a no-go: learning to stop responding to alcohol cues reduces alcohol intake via 
reduced affective associations rather than increased response inhibition. Addiction (Abingdon, England). 2012; 107(7): 1280-1287.

107. Hanlon CA, Dowdle LT, Austelle CW, et al. What goes up, can come down: Novel brain stimulation paradigms may attenuate craving and craving-related neural circuitry in substance dependent individuals. Brain Res. 2015; 1628(Pt A): 199-209.

108. Wing VC, Barr MS, Wass CE, et al. Brain stimulation methods to treat tobacco addiction. Brain Stimul. 2013; 6(3): 221-230.

109. Cho SS, Koshimori Y, Aminian K, et al. Investing in the future: stimulation of the medial prefrontal cortex reduces discounting of delayed rewards. Neuropsychopharmacology. 2015; 40(3): 546-553.

110. Schmaal L, Goudriaan AE, Joos L, et al. Neural substrates of impulsive decision making modulated by modafinil in alcoholdependent patients. Psychol Med. 2014; 44(13): 2787-2798.

111. Brown TE, Holdnack J, Saylor K, et al. Effect of atomoxetine on executive function impairments in adults with ADHD. Journal of attention disorders. 2011; 15(2): 130-138.

112. Walsh SL, Middleton LS, Wong CJ, et al. Atomoxetine does not alter cocaine use in cocaine dependent individuals: a double blind randomized trial. Drug Alcohol Depend. 2013; 130(1-3): 150-157.

113. McClure SM, Bickel WK. A dual-systems perspective on addiction: contributions from neuroimaging and cognitive training: dual-systems models of addiction. Ann NY Acad Sci. 2014; 1327(1): 62-78.

114. Passamonti L, Luijten M, Ziauddeen H, et al. Atomoxetine effects on attentional bias to drug-related cues in cocaine dependent individuals. Psychopharmacology. 2017; 234(15): 2289-2297.

115. Boettiger CA, Kelley EA, Mitchell JM, D’Esposito M, Fields HL. Now or later? An fMRI study of the effects of endogenous opioid blockade on a decision-making network. Pharmacol Biochem Behav. 2009; 93(3): 291-299.

116. Fadda P, Scherma M, Fresu A, Collu M, Fratta W. Baclofen antagonizes nicotine-, cocaine-, and morphine-induced dopamine release in the nucleus accumbens of rat. Synapse. $2003 ; \mathbf{5 0}(1)$ : $1-6$

117. Young KA, Franklin TR, Roberts DC, et al. Nipping cue reactivity in the bud: baclofen prevents limbic activation elicited by subliminal drug cues. J Neurosci. 2014; 34(14): 5038-5043.

118. Childress AR, Ehrman RN, Wang Z, et al. Prelude to passion: limbic activation by "unseen" drug and sexual cues. PLoS ONE. 2008; 3 (1): e1506.

119. Wetherill RR, Young KA, Jagannathan K, et al. The impact of sex on brain responses to smoking cues: a perfusion fMRI study. Biol Sex Differ. $2013 ; \mathbf{4}(1)$ : 9.

120. Schmidt AF, Eulenbruch T, Langer C, Banger M. Interoceptive awareness, tension reduction expectancies and self-reported drinking behavior. Alcohol Alcohol. 2013; 48(4): 472-477.

121. Craig AD. Interoception: the sense of the physiological condition of the body. Curr Opin Neurobiol. 2003; 13(4): 500-505.

122. Craig $\mathrm{AD}$. Interoception and emotion: a neuroanatomical perspective. In: Lewis M, Habiland-Jones JM, Feldman Barrett L, eds. Handbook of Emotions. New York: Guilford Press; 2007: 272-290.

123. Craig $\mathrm{AD}$. How do you feel-now? The anterior insula and human awareness. Nat Rev Neurosci. 2009; 10: 59

124. Paulus MP, Stewart JL. Interoception and drug addiction. Neuropharmacology. 2014; 76(Pt B): 342-350.

125. Bechara A, Dolan S, Hindes A. Decision-making and addiction (part II): myopia for the future or hypersensitivity to reward? Neuropsychologia. 2002; 40(10): 1690-1705.

126. Paulus MP, Tapert SF, Schuckit MA. Neural activation patterns of methamphetamine-dependent subjects during decision making predict relapse. Arch Gen Psychiatry. 2005; 62(7): 761-768.

127. Gowin JL, Harle KM, Stewart JL, Wittmann M, Tapert SF, Paulus MP. Attenuated insular processing during risk predicts relapse in early abstinent methamphetamine-dependent individuals. Neuropsychopharmacology. 2014; 39(6): 1379-1387.
128. Naqvi NH, Rudrauf D, Damasio H, Bechara A. Damage to the insula disrupts addiction to cigarette smoking. Science. 2007; 315 (5811): 531-534.

129. Naqvi NH, Gaznick N, Tranel D, Bechara A. The insula: a critical neural substrate for craving and drug seeking under conflict and risk. Ann NY Acad Sci. 2014; 1316: 53-70.

130. Lawrence EJ, Su L, Barker GJ, et al. Self-regulation of the anterior insula: reinforcement learning using real-time fMRI neurofeedback. Neuroimage. 2014; 88: 113-124.

131. Veit R, Singh V, Sitaram R, Caria A, Rauss K, Birbaumer N. Using real-time fMRI to learn voluntary regulation of the anterior insula in the presence of threat-related stimuli. Soc Cogn Affect Neurosci. $2012 ; 7(6)$ : 623-634.

132. Lee S, Ruiz S, Caria A, Veit R, Birbaumer N, Sitaram R. Detection of cerebral reorganization induced by real-time fMRI feedback training of insula activation: a multivariate investigation. Neurorehabil Neural Repair. 2011; 25(3): 259-267.

133. Pushparaj A, Hamani C, Yu W, et al. Electrical stimulation of the insular region attenuates nicotine-taking and nicotine-seeking behaviors. Neuropsychopharmacology. 2013; 38(4): 690-698.

134. Batha K, Carroll M. Metacognitive training aids decision making. Aust J Psychol. 2007; 59(2): 64-69.

135. Hauser TU, Allen M, NSPN Consortium, Rees G, Dolan RJ. Metacognitive impairments extend the perceptual decision making weaknesses in compulsivity. Sci Rep. 2017; 7(1): 1-10.

136. Lipari RN, Park-Lee E, Van Horn S. America's Need for and Receipt of Substance Use Treatment in 2015. The CBHSQ Report: September 29, 2016. Rockville, MD: Center for Behavioral Health Statistics and Quality, Substance Abuse and Mental Health Services Administration; 2016.

137. Goldstein RZ, Craig AD, Bechara A, et al. The neurocircuitry of impaired insight in drug addiction. Trends Cogn Sci. 2009; 13(9): $372-380$.

138. Moeller SJ, Fleming SM, Gan G, et al. Metacognitive impairment in active cocaine use disorder is associated with individual differences in brain structure. Eur Neuropsychopharmacol. 2016 26(4): 653-662

139. Moeller SJ, Konova AB, Parvaz MA, et al. Functional, structural, and emotional correlates of impaired insight in cocaine addiction. JAMA Psychiatry. 2014; 71(1): 61-70.

140. van der Meer L, de Vos AE, Stiekema AP, et al. Insight in schizophrenia: involvement of self-reflection networks? Schizophr Bull. 2013; 39(6): 1288-1295.

141. Balconi M, Finocchiaro R, Campanella S. Reward sensitivity, decisional bias, and metacognitive deficits in cocaine drug addiction. $J$ Addict Med. 2014; 8(6): 399-406.

142. Brevers D, Cleeremans A, Bechara A, et al. Impaired metacognitive capacities in individuals with problem gambling. J Gambl Stud. 2014; 30(1): 141-152.

143. Amador XF, Davis AS. Insight and Psychosis: Awareness of Illnes in Schizophrenia and Related Disorders. Oxford, UK: Oxford University Press; 2004

144. Orfei MD, Robinson RG, Bria P, Caltagirone C, Spalletta G Unawareness of illness in neuropsychiatric disorders: phenomenological certainty versus etiopathogenic vagueness. Neuroscientist. 2008; 14(2): 203-222.

145. Orfei MD, Piras F, Banaj N, et al. Unrealistic self-overconfidence in schizophrenia is associated with left presubiculum atrophy and impaired episodic memory. Cortex. 2017; 86: 132-139.

146. Moeller SJ, Bederson L, Alia-Klein N, Goldstein RZ. Neuroscience of inhibition for addiction medicine: from prediction of initiation to prediction of relapse. Prog Brain Res. 2016; 223: 165-188.

147. Spada MM, Caselli G, Nikcevic AV, Wells A. Metacognition in addictive behaviors. Addict Behav. 2015; 44: 9-15. 
148. Wells A, Simons M. Metacognitive Therapy. Wiley Online Library; 2009.

149. Wells A, King P. Metacognitive therapy for generalized anxiety disorder: an open trial. J Behav Ther Exp Psychiatry. 2006; 37(3): 206-212.

150. Wells A, Papageorgiou C. Brief cognitive therapy for social phobia: a case series. Behav Res Ther. 2001; 39(6): 713-720.

151. Wells A, Colbear JS. Treating posttraumatic stress disorder with metacognitive therapy: a preliminary controlled trial. J Clin Psychol. 2012; 68(4): 373-381.

152. Fisher PL, Wells A. Metacognitive therapy for obsessivecompulsive disorder: A case series. J Behav Ther Exp Psychiatry. 2008; 39(2): 117-132.

153. Moritz S, Woodward TS, Balzan R. Is metacognitive training for psychosis effective? Expert Rev Neurother. 2016; 16(2): 105-107.

154. Spada MM, Caselli G, Nikčević AV, Wells A. Metacognition in addictive behaviors. Addict Behav. 2015; 44: 9-15.

155. Eichner C, Berna F. Acceptance and efficacy of metacognitive training (MCT) on positive symptoms and delusions in patients with schizophrenia: a meta-analysis taking into account important moderators. Schizophr Bull. 2016; 42(4): 952-962.

156. Normann N, van Emmerik AAP, Morina N. The efficacy of metacognitive therapy for anxiety and depression: a metaanalytic review. Depress Anxiety. 2014; 31(5): 402-411.

157. Spada MM, Wells A. A metacognitive model of problem drinking. Clin Psychol Psychother. 2009; 16(5): 383-393.

158. Premack D, Woodruff G. Does the chimpanzee have a theory of mind? Behav Brain Sci. 1978; 1(4): 515-526.

159. Tay SA, Hulbert CA, Jackson HJ, Chanen AM. Affective and cognitive theory of mind abilities in youth with borderline personality disorder or major depressive disorder. Psychiatry Res. 2017; 255: 405-411.

160. Mitchell RLC, Phillips LH. The overlapping relationship between emotion perception and theory of mind. Neuropsychologia. 2015; 70: $1-10$.

161. Bosia M, Riccaboni R, Poletti S. Neurofunctional correlates of theory of mind deficits in schizophrenia. Curr Top Med Chem. 2012; 12(21): 2284-2302.

162. Flavell JH. Theory-of-mind development: retrospect and prospect. Merrill Palmer Quart. 2004; 50(3): 274-290.

163. Flavell JH. Cognitive development: children's knowledge about the mind. Annu Rev Psychol. 1999; 50: 21-45.

164. Ciaramidaro A, Bölte S, Schlitt S, et al. Schizophrenia and autism as contrasting minds: neural evidence for the hypo-hyperintentionality hypothesis. Schizophr Bull. 2015; 41(1): 171-179.

165. Happé F, Frith U. Annual research review: towards a developmental neuroscience of atypical social cognition. J Child Psychol Psychiatry. 2014; 55(6): 553-577.

166. Langdon R, Connors MH, Connaughton E. Social cognition and social judgment in schizophrenia. Schizophr Res Cogn. 2014; 1(4): 171-174.

167. Okruszek $€$, Bala A, Wordecha M, et al. Social cognition in neuropsychiatric populations: a comparison of theory of mind in schizophrenia and mesial temporal lobe epilepsy. Sci Rep. 2017; $7(1): 484$.

168. Downey LE, Blezat A, Nicholas J, et al. Mentalising music in frontotemporal dementia. Cortex. 2013; 49(7): 1844-1855.
169. Schmidt SJ, Mueller DR, Roder V. Social cognition as a mediator variable between neurocognition and functional outcome in schizophrenia: empirical review and new results by structural equation modeling. Schizophr Bull. 2011; 37(suppl_2): S41-S54.

170. Fett A-KJ, Viechtbauer W, Dominguez M-d-G, Penn DL, van Os J, Krabbendam L. The relationship between neurocognition and social cognition with functional outcomes in schizophrenia: a meta-analysis. Neurosci Biobehav Rev. 2011; 35(3): 573-588.

171. Barbato M, Liu L, Penn DL, et al. Social cognition as a mediator between neurocognition and functional outcome in individuals at clinical high risk for psychosis. Schizophr Res. 2013; 150(2): 542546.

172. Francesconi M, Minichino A, Carrión RE, et al. Theory of Mind as a mediator variable between neurocognition and functioning in young individuals in treatment with secondary services for nonpsychotic disorders. Psychiatry Res. 2016; 246: 415-420.

173. Pluta A, Kulesza M, Grzegorzewski P, Kucharska K. Assessing advanced theory of mind and alexithymia in patients suffering from enduring borderline personality disorder. Psychiatry Res. 2018; 261: 436-441.

174. Bora E, Zorlu N. Social cognition in alcohol use disorder: a metaanalysis. Addiction (Abingdon, England). 2017; 112(1): 40-48.

175. Sanvicente-Vieira B, Kluwe-Schiavon B, Corcoran R, GrassiOliveira R. Theory of mind impairments in women with cocaine addiction. J Stud Alcohol Drugs. 2017; 78(2): 258-267.

176. Kemmis L, Hall JK, Kingston R, Morgan MJ. Impaired fear recognition in regular recreational cocaine users. Psychopharmacology. 2007; 194(2): 151-159.

177. Preller KH, Hulka LM, Vonmoos M, et al. Impaired emotional empathy and related social network deficits in cocaine users. Addict Biol. 2014; 19(3): 452-466.

178. Roser P, Lissek S, Tegenthoff M, Nicolas V, Juckel G, Brüne M. Alterations of theory of mind network activation in chronic cannabis users. Schizophr Res. 2012; 139(1): 19-26.

179. Baron-Cohen S, Wheelwright S, Hill J, Raste Y, Plumb I. The "Reading the Mind in the Eyes" Test revised version: a study with normal adults, and adults with Asperger syndrome or high-functioning autism. J Child Psychol Psychiatry. 2001; 42(2): 241-251.

180. Shamay-Tsoory SG, Shur S, Barcai-Goodman L, Medlovich S, Harari H, Levkovitz Y. Dissociation of cognitive from affective components of theory of mind in schizophrenia. Psychiatry Res. 2007; 149(1): 11-23.

181. Canty AL, Neumann DL, Shum DHK. Using virtual reality to assess theory of mind subprocesses and error types in early and chronic schizophrenia. Schizophr Res Cogn. 2017; 10: 15-19.

182. Montag C, Haase L, Seidel D, et al. A pilot RCT of psychodynamic group art therapy for patients in acute psychotic episodes: feasibility, impact on symptoms and mentalising capacity. PLoS ONE. 2014; 9(11): e112348.

183. Lisdahl KM, Sher KJ, Conway KP, et al. Adolescent brain cognitive development (ABCD) study: overview of substance use assessment methods. Dev Cogn Neurosci. 2018; 32: 80-96.

184. Kwako LE, Bickel WK, Goldman D. Addiction biomarkers: dimensional approaches to understanding addiction. Trends $\mathrm{Mol}$ Med. 2018; 24(2): 121-128.

185. Caspi A, Houts RM, Belsky DW, et al. The p factor: one general psychopathology factor in the structure of psychiatric disorders? Clin Psychol Sci. 2014; 2(2): 119-137. 